\title{
PEDAGOGIA, ARQUITETURA E BIBLIOTECONOMIA: PROCESSOS PEDAGÓGICOS PARA REESTRUTURAR UMA BIBLIOTECA ESCOLAR
}

\author{
PEDAGOGÍA, ARQUITECTURA Y BIBLIOTECOLOGÍA: \\ PROCESOS PEDAGÓGICOS PARA ESTRUCTURAR UNA \\ BIBLIOTECA ESCOLAR
}

\author{
Rovilson José da Silva* \\ Teba Silva Yllana** \\ Felipe Martins Menck ${ }^{\star \star \star}$ \\ Giovana Takahashi de Oliveira ${ }^{\star \star \star \star}$
}

\begin{abstract}
RESUMO
Introdução: As bibliotecas escolares em geral ainda não conseguiram propiciar, aos seus leitores, um espaço que possam sentir-se acolhidos física, psicológica e culturalmente, e a biblioteca do Instituto Estadual de Educação de Londrina (IEEL) não é uma exceção.

Objetivo: Disseminar as interferências realizadas na biblioteca do IEEL pela equipe do Projeto de extensão "Formação do Mediador de leitura em escola pública" no período de 2012 a 2015.

Metodologia: Os procedimentos foram construídos utilizando metodologia colaborativa multidisciplinar e tiveram a participação de docentes e discentes da UEL, direção, equipe pedagógica e atendentes de biblioteca do IEEL.

Resultados: Foram realizadas interferências na readequação espacial da biblioteca escolar associada à mediação pedagógica da leitura, visando à formação de leitores. Para tanto ocorreram inúmeras reuniões de estudo e pesquisa, discussão a respeito de biblioteca, seu espaço e suas funções, reconhecimento do espaço biblioteca no IEEL e na Biblioteca Central da UEL, construção do projeto arquitetônico confortável e aprazível.

Conclusões: As primeiras readequações espaciais da biblioteca dessa escola pública já têm surtido efeito, pois vêm atendendo às necessidades de uso desse ambiente pela comunidade escolar de forma satisfatória.
\end{abstract}

* Doutor em Educação pela Universidade Estadual Paulista "Júlio de Mesquita Filho" (Unesp), campus de Marília. Professor do Departamento de Educação da Universidade Estadual de Londrina (UEL). E-mail: rovilson@uel.br.

** Doutoranda no Programa de Pós-Graduação em Urbanismo pela Universidade Federal do Rio de Janeiro (UFRJ). Professora do Departamento de Arquitetura e Urbanismo da Universidade Estadual de Londrina (UEL). E-mail: teba@uel.br.

*** Bolsista de Extensão e graduando em Arquitetura pela Universidade Estadual de Londrina (UEL). E-mail: felipemenck@gmail.com.

**** Bolsista de Extensão e graduanda em Arquitetura pela Universidade Estadual de Londrina (UEL). E-mail: oli.giovanatakahashi@gmail. 
Rovilson José da Silva; Teba Silva Yllana; Felipe Martins Menck; Giovana Takahashi de Oliveira

Pedagogia, arquitetura e biblioteconomia: processos pedagógicos para reestruturar uma biblioteca escolar

Palavras-chave: Biblioteca escolar. Processos Pedagógicos. Reestruturação arquitetônica. Pedagogia. Arquitetura. Biblioteconomia.

\section{INTRODUÇÃO}

O projeto de extensão "Formação do Mediador de Leitura em Escola Pública" realizado no Instituto Estadual de Educação de Londrina (IEEL), desde 2012, tem como proposta a readequação espacial da biblioteca escolar associada à mediação pedagógica da leitura, visando à formação de leitores.

Ele se inicia com a participação apenas de um docente do curso de Pedagogia da Universidade Estadual de Londrina, mas, aos poucos, outras áreas, isto é, Arquitetura e Biblioteconomia (cada um com sua especificidade) foram convidadas a integrar a equipe. Posteriormente, alunos das áreas envolvidas foram incorporados ao projeto.

A preocupação, desde o início, não era apenas organizar a biblioteca espacial ou pedagogicamente, mas realizar a reconstrução do espaço para que alunos e professores pudessem usufruir de um local com acervo completo e organizado, possibilitando, assim, o acesso à informação.

Outra perspectiva era "[...] permitir que a biblioteca tenha espaço para que, ao ser usada durante e após as aulas, gere outro tipo de relação entre o cidadão e a leitura, o cidadão em formação e 0 conhecimento." (SILVA, 2012, p. 163).

O processo pedagógico de inserção da biblioteca pressupõe que esse espaço seja incorporado à escola, de modo que cada envolvido, aluno ou equipe escolar, tem na biblioteca uma aliada na formação do ser humano. A biblioteca, nesse contexto, pertence à comunidade escolar, contribuindo para que surjam leitores, pesquisadores, enfim, para constituir sujeitos mais críticos de si mesmos e do mundo.

Os estudos a respeito das bibliotecas escolares ainda precisam avançar e, neles, há muito que se investir nos aspectos espaciais e pedagógicos da biblioteca, ou melhor, que o processo de transformação 
Rovilson José da Silva; Teba Silva Yllana; Felipe Martins Menck; Giovana Takahashi de Oliveira

Pedagogia, arquitetura e biblioteconomia: processos pedagógicos para reestruturar uma biblioteca escolar

desse espaço passe por uma concepção pedagógica de biblioteca, de formação de crianças e de adolescentes.

Esse artigo apresenta parte do trabalho que tem sido desenvolvido na biblioteca escolar de uma instituição pública. Nele serão apresentados: a metodologia aplicada no projeto de extensão para a construção de conhecimento e propostas sobre o assunto, os processos realizados para a delineação do projeto de reestruturação arquitetônica e a quais foram as estratégias de divulgação dos resultados em seminários temáticos para a comunidade universitária.

\section{TRABALHO EM PARCERIA, RESULTADOS POTENCIALIZADOS}

Assim, para promover a conscientização da importância do ambiente da biblioteca para a formação de cidadãos, é necessário envolver a comunidade escolar como um todo no processo de reorganização e atuar em diferentes frentes para possibilitar a integração desse espaço no cotidiano dos alunos e professores da escola.

Grande parte do sucesso que vem sendo observado na reestruturação da biblioteca contemplada pelo projeto de extensão se deu pela atuação conjunta de três áreas do conhecimento: pedagogia, arquitetura e biblioteconomia. A abordagem conjunta garante a segurança para a comunidade escolar de que a reestruturação está sendo desenvolvida em seus termos, o que maximiza os benefícios dessa reforma, já que cada escola tem particularidades e necessidades diferenciadas.

Para leitura e discussão de conceitos que fundamentaram ações no projeto, foram utilizadas publicações de especialistas em diversas áreas do conhecimento, em especial, Vidulli (1998); Barbalho (2012) e Silva (2012) que balizaram a adoção de uma metodologia para o desenvolvimento do projeto arquitetônico. Cada trabalho lido auxiliou na visualização da biblioteca em diferentes perspectivas, apontando para 
Rovilson José da Silva; Teba Silva Yllana; Felipe Martins Menck; Giovana Takahashi de Oliveira

Pedagogia, arquitetura e biblioteconomia: processos pedagógicos para reestruturar uma biblioteca escolar

diversos aspectos que compõem esse ambiente e suas necessidades para que ele se tornasse atrativo e eficiente.

Paralelos ao subsídio bibliográfico foram realizados levantamentos de campo para a equipe entrar em contato com o ambiente escolar por meio de visitas guiadas pelos professores orientadores e pela direção da escola onde a biblioteca está inserida. Nessas visitas, realizadas após a manutenção emergencial do forro da edificação, priorizou-se o reconhecimento do espaço da biblioteca, realizando medições para gerar desenhos técnicos condizentes com a realidade, como plantas, cortes e elevações, que serviriam como base para o desenvolvimento de futuras propostas para o ambiente.

Nessa etapa, foram identificados que muitos espaços da biblioteca estavam subutilizados, ao mesmo tempo em que o acervo estava em local muito apertado, inadequado para realizar manutenção, catalogação e recebimento de novos volumes, indicando a necessidade urgente de reorganização do espaço.

$\mathrm{Na}$ visita seguinte, foi priorizado o contato com a comunidade escolar. Por isso, os acadêmicos foram divididos em três grupos, para visitar a escola em seus três turnos de funcionamento. Assim, por meio da observação da frequência no espaço e contato com diferentes membros da comunidade escolar, como alunos, docentes e colaboradores, foi possível identificar a rotina e o perfil dos estudantes e funcionários, bem como suas expectativas e necessidades em relação ao espaço.

Neste contexto, conhecer os usuários de um ambiente é essencial no processo de estruturação de um projeto, pois " $A$ arquitetura, ao demarcar as fronteiras e limites do homem no espaço construído, opera de forma globalizante na relação espaço-tempo do fruidor e age ativamente sobre sua mobilidade corporal." (BARBALHO, 2012, p. 95).

Constatou-se que era necessário maior incentivo à leitura para que os alunos explorassem mais o acervo existente da biblioteca e foram identificadas diferenças na utilização entre os turnos: os alunos da 
Rovilson José da Silva; Teba Silva Yllana; Felipe Martins Menck; Giovana Takahashi de Oliveira

Pedagogia, arquitetura e biblioteconomia: processos pedagógicos para reestruturar uma biblioteca escolar

tarde frequentavam mais a biblioteca que os alunos da manhã, por exemplo. Além disso, algumas sugestões para a readequação do espaço foram dadas espontaneamente pelos próprios alunos, como a mudança do local do balcão de empréstimo e melhoria de ventilação, entre outras sugestões que usuários com maior frequência no espaço, conhecedores das deficiências e possíveis potencialidades do espaço, poderiam dar.

Presenciou-se também a visita de professores com suas turmas durante o período de aula na biblioteca. Segundo relatos dos professores responsáveis pela biblioteca, essas visitas foram se tornando mais assíduas após os contatos iniciais entre o projeto de extensão e a escola, demonstrando a vontade de alunos e professores de se apropriarem desse espaço de conhecimento e descobertas que é a biblioteca escolar.

Num ambiente de biblioteca a identificação do acervo, das mesas e do balcão deve ser de fácil acesso para todos, assim como se faz necessário que a área técnica para catalogação e restauro, armários para arquivos e o espaço para funcionários estejam adequados. Para os participantes do Projeto chegarem a esse entendimento, foi organizada uma visita à Biblioteca Central da UEL. Ali foram vistos todos os ambientes necessários para uma biblioteca funcionar adequadamente. Apesar de a biblioteca ter uma escala maior que a biblioteca escolar do Projeto, a visita foi muito importante para entender o mecanismo de funcionamento interno da biblioteca e seus espaços específicos para tratamento do acervo, que normalmente não ficam à vista do público. $A$ partir do conhecimento adquirido, foi possível identificar e dividir esses espaços dentro da biblioteca do IEEL com mais funcionalidade e organicidade para a utilização de todos.

Vale destacar que ao se projetar qualquer obra ou edifício, é muito importante, além do estudo de especialistas no assunto e visitas ao local da intervenção, buscar conhecer outros espaços projetados com funções semelhantes para se verificar as soluções adotadas naquele projeto. Essa técnica é chamada de análise de correlatos, que 
Rovilson José da Silva; Teba Silva Yllana; Felipe Martins Menck; Giovana Takahashi de Oliveira

Pedagogia, arquitetura e biblioteconomia: processos pedagógicos para reestruturar uma biblioteca escolar

pode ocorrer com base em bibliografias específicas ou em visitas técnicas. No caso deste projeto de extensão, optou-se pelas duas maneiras: visita a uma biblioteca em atividade e análise de bibliotecas escolares e não escolares, nacionais e internacionais, com o intuito de identificar diferentes formas de organização espacial e usos. Como o projeto de extensão propõe a reforma de um edifício já existente com recursos limitados, foi necessário adequar e traduzir as boas ideias e inspirações apreendidas pela observação desses outros projetos às condicionantes apresentadas da melhor forma possível.

3 TRAJETÓRIAS PRELIMINARES: das primeiras ideias ao delineamento do projeto de reestruturação arquitetônica

Os colaboradores do projeto de extensão (docentes, discentes, pedagogos e funcionários da escola) passaram pela formação nos ensinos fundamental e médio tanto em instituições públicas como privadas. Essa pluralidade na formação dos participantes proporcionou o compartilhamento de distintas experiências vivenciadas no espaço da biblioteca escolar. Nesse contexto, reiterou-se a importância das oportunidades pedagógicas de uso e convivência proporcionadas pelo ambiente da biblioteca na fase escolar como elemento marcante para 0 desenvolvimento do aluno como cidadão.

A biblioteca da escola é um espaço pedagógico com características sociais e de conhecimento, pois pode comportar apresentações entre os alunos, aulas diferenciadas ao ar livre, exposições de trabalhos produzidos na escola, assim como outros usos do espaço da biblioteca de forma inovadora e atraente. Esses diferentes usos proporcionam a vivência de momentos únicos, que passarão a fazer parte da vida do aluno e nunca serão esquecidos. Ao se inserir essas atividades no espaço da biblioteca, é possível criar um vínculo especial entre aluno-biblioteca e aluno-leitura.

Como parte da metodologia de elaboração das primeiras ideias para a reestruturação do espaço da biblioteca, foi estimulado o 
Rovilson José da Silva; Teba Silva Yllana; Felipe Martins Menck; Giovana Takahashi de Oliveira

Pedagogia, arquitetura e biblioteconomia: processos pedagógicos para reestruturar uma biblioteca escolar

compartilhamento de experiências vividas no espaço da biblioteca escolar pelos colaboradores do projeto. Assim, algumas atividades pensadas nesse exercício eram comuns a vários participantes do projeto, como apresentações, teatro, paródias, jograis, entre outros, portanto foi constatada a importância de se ter um espaço informal onde atividades como essas possam ser realizadas. Por isso, no projeto desenvolvido pelos extensionistas, trabalhou-se também com a reestruturação arquitetônica do pátio, localizado atrás do prédio da biblioteca, com a perspectiva de seu uso em prol da dinâmica pedagógica e cultural escolar.

Esse é um entre outros exemplos de como as experiências pessoais também enriqueceram e ajudaram a moldar o projeto discutido e apresentado para a comunidade escolar. Após debater as experiências pessoais, foi proposto que cada colaborador elaborasse sua sugestão de setorização e fluxograma do espaço existente da biblioteca e que defendesse, ao apresentar aos colegas e orientadores, sua proposta. Desse modo, foi possível perceber o quanto as experiências pessoais na utilização de um espaço de leitura e informação refletiram no processo de construção do projeto de cada um.

Muitas das ideias sugeridas nessa etapa, ao atenderem também as necessidades dos utilizadores da biblioteca, foram acatadas, aprimoradas e utilizadas no projeto.

A seguir serão apresentadas, em forma de figuras, as propostas realizadas pelos acadêmicos, na figura 1, por exemplo, é perceptível as alterações como: instalação de rampa acessível na entrada, a localização de áreas administrativas, a necessidade de revitalização para o usos e acesso da sala lateral e utilização do pátio externo como espaço de leitura informal, apresentações e intervenções socioculturais com acesso lateral. 
Rovilson José da Silva; Teba Silva Yllana; Felipe Martins Menck; Giovana Takahashi de Oliveira

Pedagogia, arquitetura e biblioteconomia: processos pedagógicos para reestruturar uma biblioteca escolar

Figura 1: Estudo preliminar (A) elaborado para a biblioteca escolar do IEEL, em planta

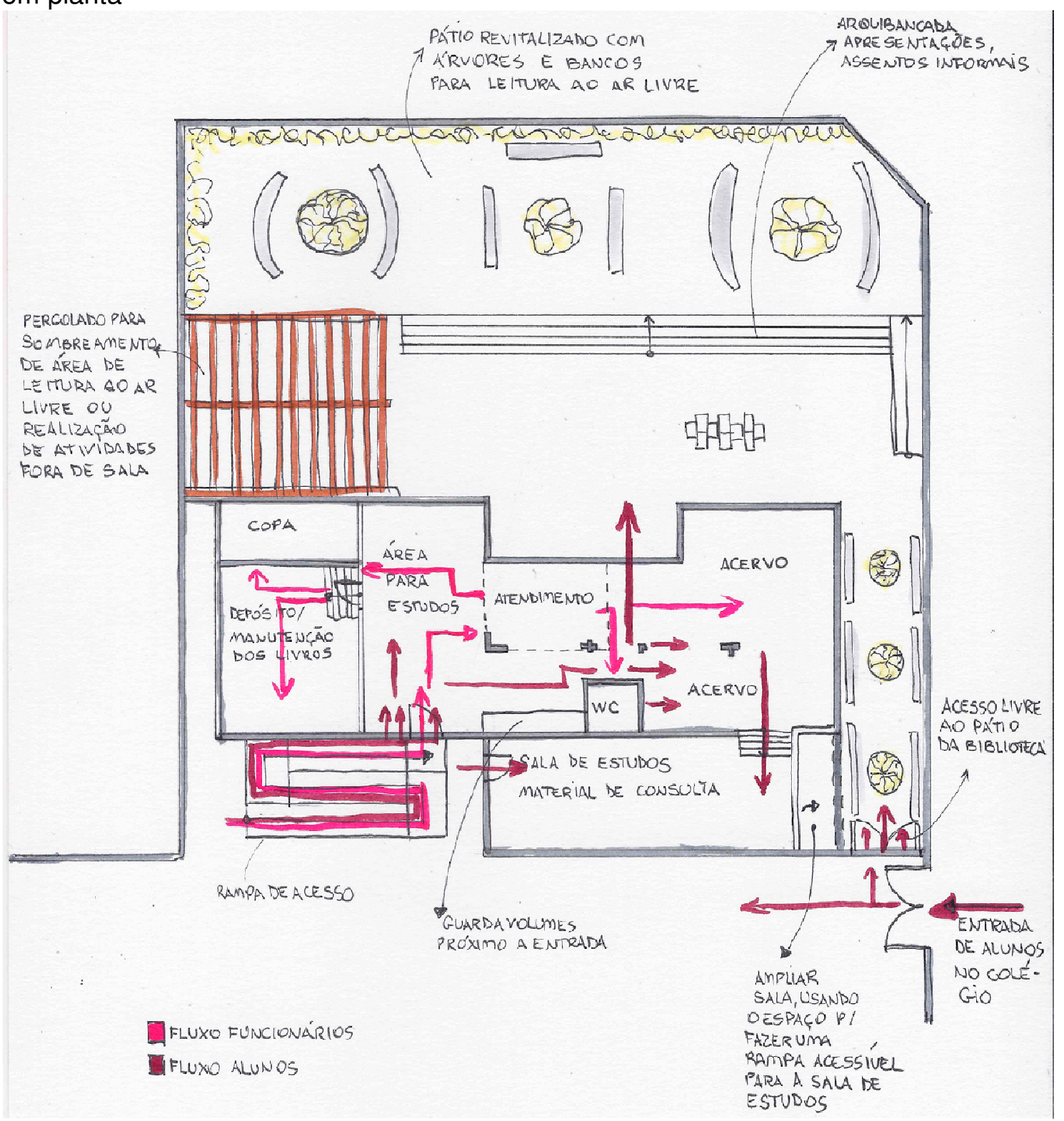

Fonte: Ribeiro (2014).

Quanto a figura 2, nela apresenta-se a alteração no local do banheiro para melhor aproveitamento do espaço e localização de acervo, depósito e área de estudo. 
Rovilson José da Silva; Teba Silva Yllana; Felipe Martins Menck; Giovana Takahashi de Oliveira

Pedagogia, arquitetura e biblioteconomia: processos pedagógicos para reestruturar uma biblioteca escolar

Figura 2: Estudo preliminar (B) elaborado para a biblioteca escolar do IEEL, em planta

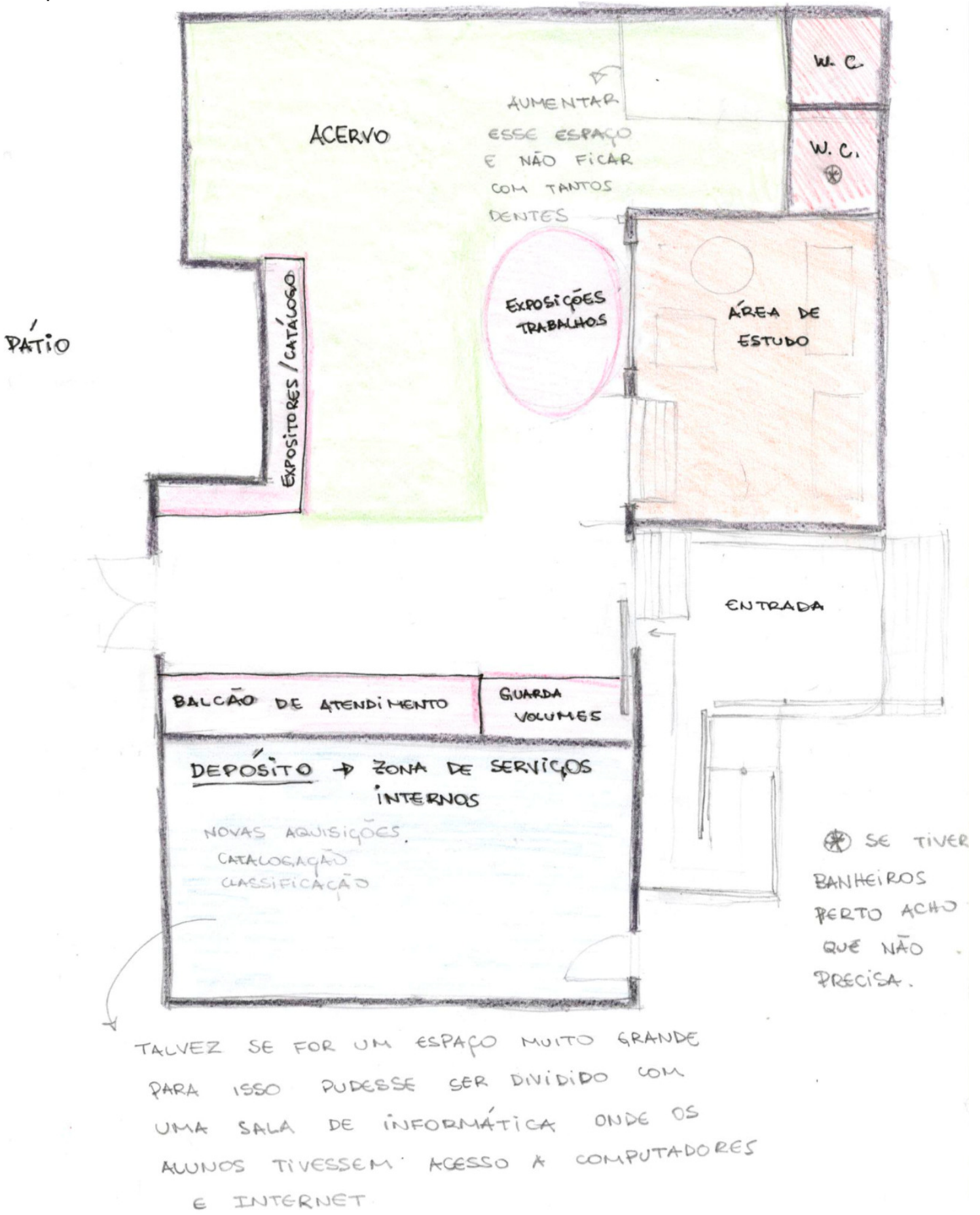

Fonte: Oliveira (2014).

Verificando a área mais abordada na proposta de cada estudante nessa etapa, foram criados três grupos de trabalho distintos e complementares para a elaboração do anteprojeto, tendo como base, 
Rovilson José da Silva; Teba Silva Yllana; Felipe Martins Menck; Giovana Takahashi de Oliveira

Pedagogia, arquitetura e biblioteconomia: processos pedagógicos para reestruturar uma biblioteca escolar

mas não se limitando a ela, a metodologia proposta por Vidulli (1998, p.21, tradução nossa):

1 - refere-se ao funcionamento geral da biblioteca, isto é, à programação do serviço que, de acordo com o contexto e os usuários a que se destina, pode ser diferente em cada caso. As escolhas deverão acontecer levando em conta, entre outros aspectos, as possíveis mudanças nas necessidades dos usuários em médio prazo.

2 - refere-se à dimensão e aos requisitos que o espaço e mobiliário devem cumprir para permitir o correto desenvolvimento das funções previstas [...], assim como à distribuição de espaço que respeite a necessidade de inter-relação entre as funções (programas de edificação e de planejamento de espaço).

3 - refere-se à imagem da biblioteca, a sua qualidade formal, os materiais, as cores e as instalações, etc. Todos esses elementos devem estar em consonância com a legislação vigente para edificações de cada localidade.

4 - refere-se à escolha do mobiliário, os complementos, iluminação, equipamentos, etc.

Cada grupo ficou responsável por uma das fases apresentadas por Vidulli (1998, p. 21), com exceção à primeira fase, pois a programação do serviço deveria ser norteadora de toda e qualquer proposta desenvolvida pelos grupos designados, devendo refletir em todas as decisões tomadas para a elaboração do anteprojeto.

Assim, um grupo ficou encarregado da otimização da fluidez no espaço interno, por meio do rearranjo da localização dos setores da biblioteca e eliminação de eventuais barreiras físicas que impediriam a utilização plena do espaço, incluindo nesse âmbito os acessos da escola ao interior da construção, propondo soluções para garantir a acessibilidade. Ainda, foram identificados, os sistemas construtivos utilizados na edificação original e expansões da biblioteca e, em sequência, foi realizado um levantamento preliminar dos elementos estruturais presentes na biblioteca, como vigas e pilares, que não podem ser relocados.

O outro grupo ficou responsável pela revitalização da imagem da biblioteca e do pátio interno, adjacente à sua edificação. Para se 
Rovilson José da Silva; Teba Silva Yllana; Felipe Martins Menck; Giovana Takahashi de Oliveira

Pedagogia, arquitetura e biblioteconomia: processos pedagógicos para reestruturar uma biblioteca escolar

redefinir a imagem da biblioteca foi proposta, de forma lúdica, a aplicação na fachada de cores alegres e vivas, com materiais e texturas diferentes, como ripas de madeira, para transmitirem diferentes sensações a quem a visualiza. Na reconfiguração do pátio interno foram definidos usos para esse espaço, tendo como maior base as experiências pessoais dos colaboradores, bem como os estudos a acerca de espaço informal, adjacente a uma biblioteca escolar destinada à criança e ao adolescente.

A definição de mobiliário e iluminação seguros e adequados aos usuários da biblioteca, bem como análises de conforto térmico e ventilação, tarefas da responsabilidade do terceiro grupo. Foram realizadas pesquisas para definir os tipos de estantes, mesas, cadeiras e expositores com dimensões e materiais mais adequados para a faixa etária dos alunos que utilizam o local, tendo como referência mobiliários existentes, com dados fornecidos por fabricantes na Internet. A definição dos mobiliários mais adequados levou em conta o conforto e a segurança dos usuários, e sua disposição no espaço foi proposta de modo a consolidar a setorização interior da biblioteca.

A junção de toda a pesquisa e definições dessa etapa resultaria na elaboração de anteprojeto com linguagem gráfica bi e tridimensional, com o auxílio de softwares como Google SketchUp e Autodesk AutoCAD, entre outros.

4 PROPOSTAS: adequações e suas justificativas

Uma produção arquitetônica não é ingênua, pelo contrário, ela se articula para colocar-se, de certo modo, no dia a dia daquele que ela abriga e que convive com suas formas interativa e subjetivamente. (BARBALHO, 2012, p. 96).

Nessa seção, apresentam-se as mudanças propostas em cada parte da biblioteca para a reestruturação do espaço físico da biblioteca escolar designada pelo projeto de extensão, bem como a concepção que embasou essas decisões. 
Rovilson José da Silva; Teba Silva Yllana; Felipe Martins Menck; Giovana Takahashi de Oliveira

Pedagogia, arquitetura e biblioteconomia: processos pedagógicos para reestruturar uma biblioteca escolar

Começando pela fachada, ela não se destacava dos outros edifícios do entorno, nada indicava a presença da biblioteca, dificultando sua identificação pelos alunos. Além da falta de sinalização, a rampa de acesso à biblioteca colocava em risco seus usuários devido à sua grande declividade, causando acidentes. Portanto, inicialmente pensada no entorno da fachada, com acesso pelo pátio atrás da biblioteca, a rampa foi repensada e inserida no acesso frontal após sugestão da escola, conforme apresentando na figura 3.

Figura 3: Primeira proposta da fachada, ainda sem rampa do acesso principal

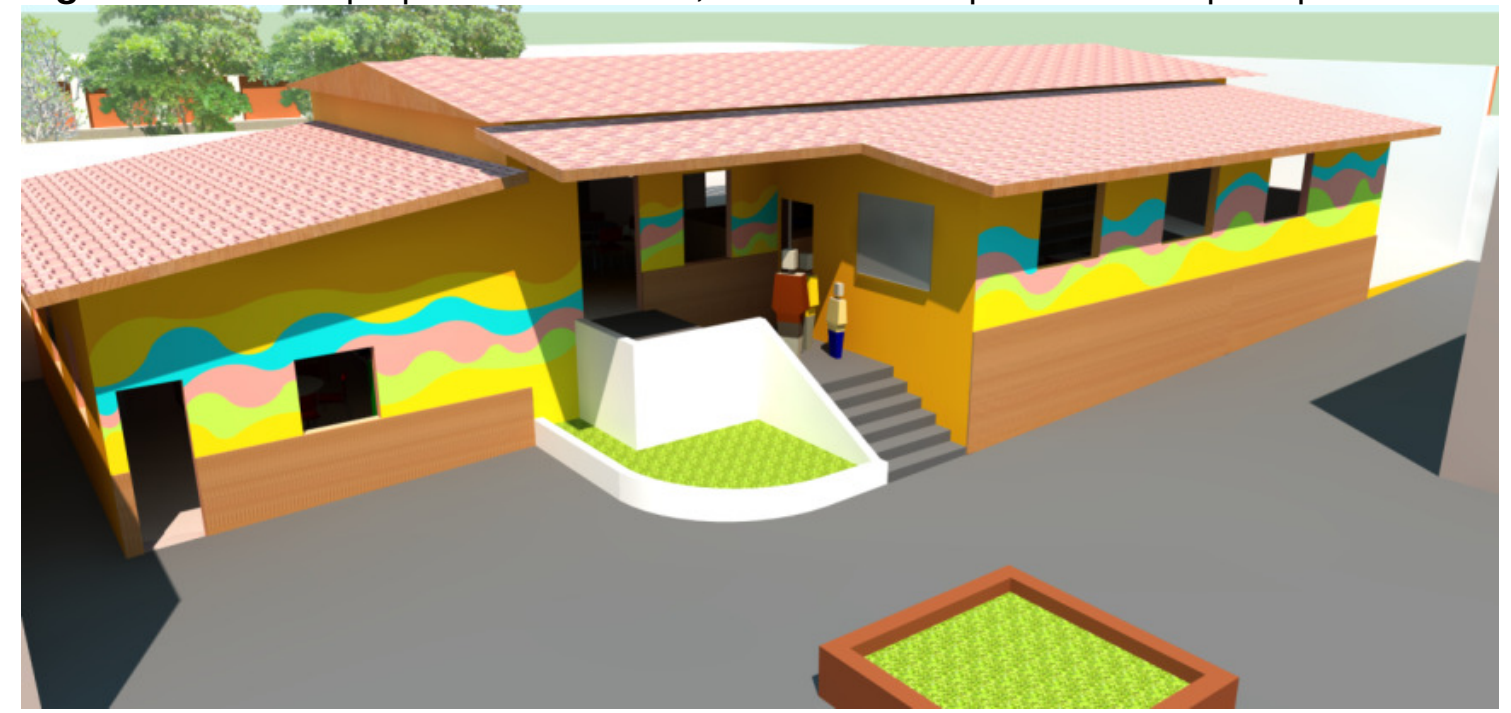

Fonte: Imagem gerada em SketchUp, acervo dos autores.

Controle de compra, doação, permuta, catalogação, reparo e organização dos livros são algumas das atividades intrínsecas ao funcionamento de qualquer biblioteca e, portanto, demandam um espaço reservado a elas. Para esse fim, uma sala que antes servia apenas como depósito de carteiras velhas e papéis foi reativada e projetada também como um lugar de descanso dos funcionários da biblioteca, permitindo o diálogo e a troca de ideias entre eles, isso pode ser observado na figura 4. 
Rovilson José da Silva; Teba Silva Yllana; Felipe Martins Menck; Giovana Takahashi de Oliveira

Pedagogia, arquitetura e biblioteconomia: processos pedagógicos para reestruturar uma biblioteca escolar

Figura 4: Proposta de sala de tratamento da informação e área de descanso dos funcionários

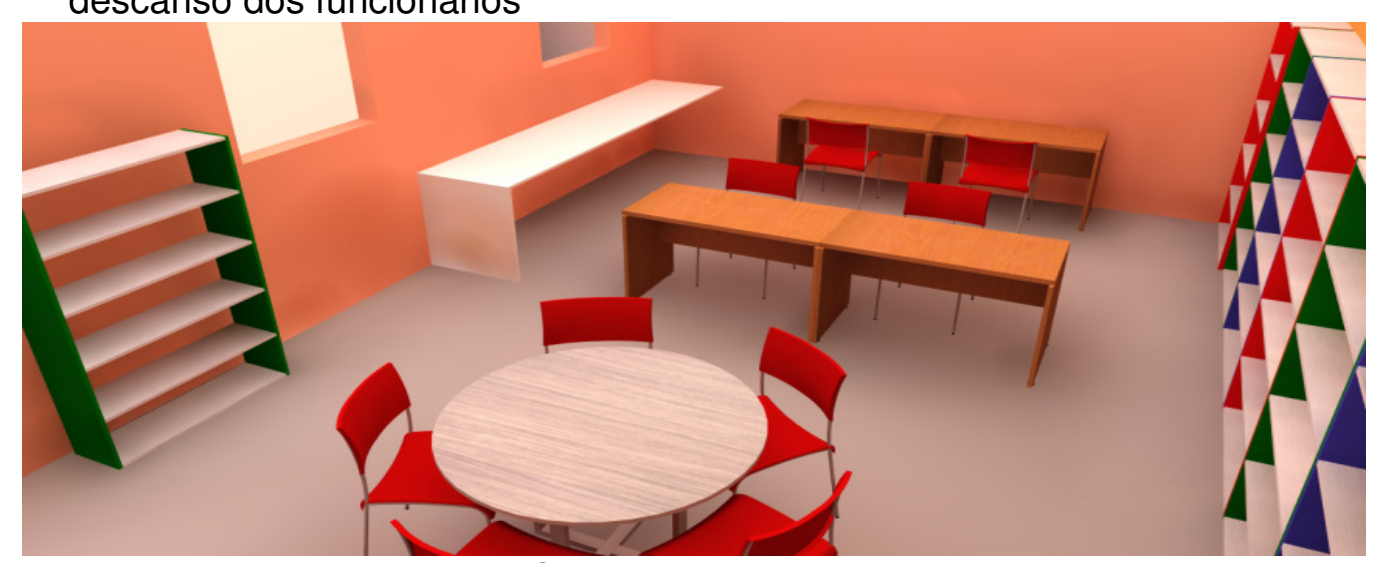

Fonte: Imagem gerada em SketchUp, acervo dos autores.

No interior da biblioteca, os ambientes eram muito fragmentados por paredes, por isso, foram retiradas aquelas que não prejudicariam a estrutura, resultando em um ambiente mais leve e amplo. $\mathrm{Na}$ imagem seguinte (figura 5), as paredes em amarelo estão projetadas para serem demolidas, alterando drasticamente a configuração do espaço e integrando a sala de estudo individual, antes sem utilização, com o resto da biblioteca através de uma rampa interna para garantir a acessibilidade universal.

Figura 5: Proposta da biblioteca já na planta baixa do projeto executivo.

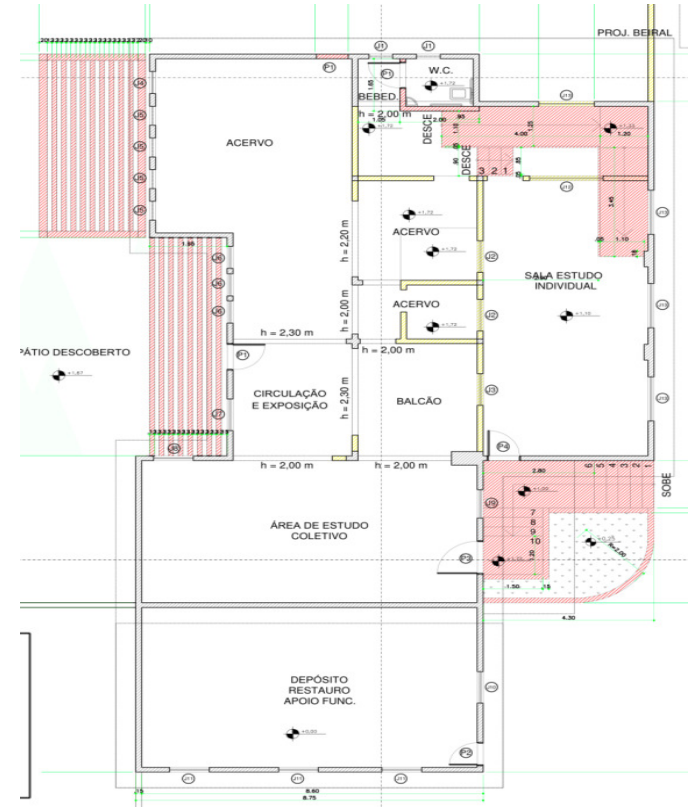

Fonte: Planta da biblioteca realizada em AutoCad pelos extensionistas. 
Rovilson José da Silva; Teba Silva Yllana; Felipe Martins Menck; Giovana Takahashi de Oliveira

Pedagogia, arquitetura e biblioteconomia: processos pedagógicos para reestruturar uma biblioteca escolar

Após a retirada das paredes, o interior foi setorizado em quatro áreas distintas: o acervo, o estudo coletivo, o estudo individual e o balcão. O acervo se manteve setorizado no mesmo local, mas ocupa agora também outros espaços adjacentes criados pela demolição das paredes, permitindo melhor organização dos livros e maior segurança devido à troca das estantes atuais por estantes com fixação correta. Cores, altura, distribuição de móveis estão expostas na figura 6.

Figura 6: Proposta de organização do acervo

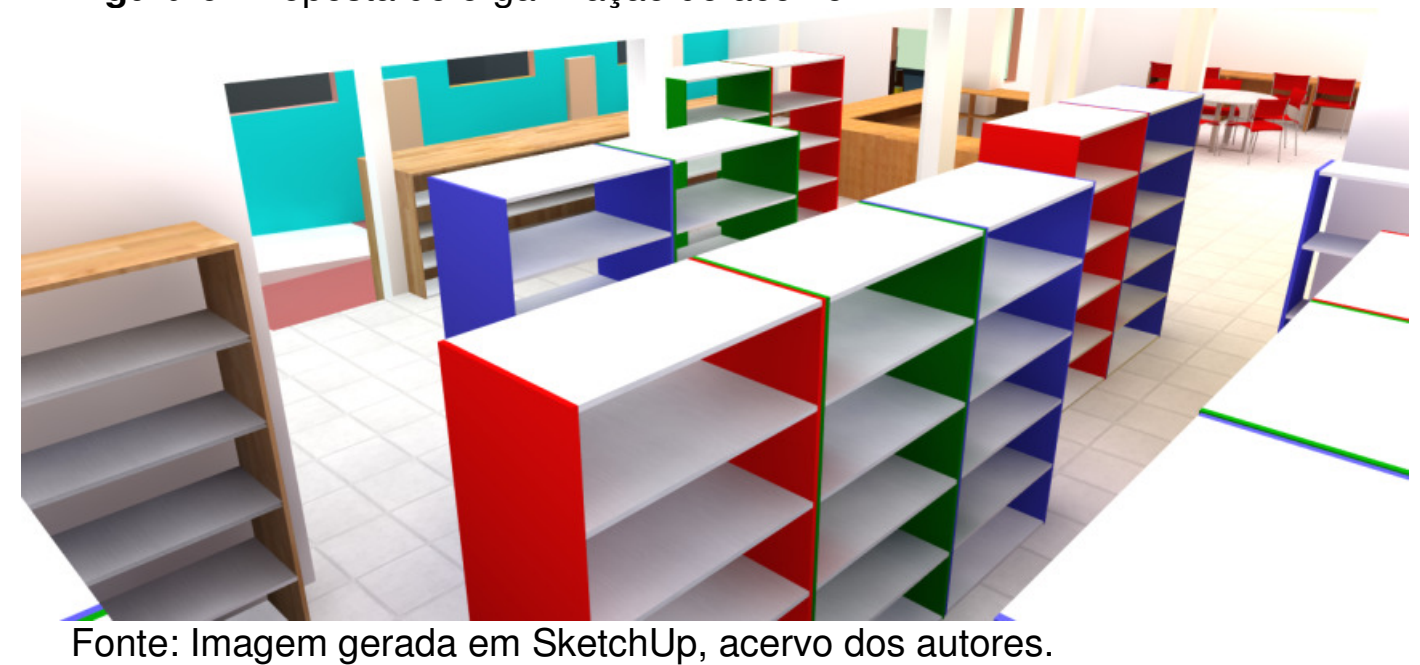

O espaço do estudo coletivo (figura 7) foi pensado para permitir o encontro e a troca de ideias, servindo também como suporte nas aulas ministradas dentro da biblioteca. Outro setor, de equivalente importância, é o de estudo individual, no nível inferior, onde é proporcionado para o aluno um espaço tranquilo para estudos e leituras. Esses ambientes podem ser utilizados nos períodos letivo e inverso, incentivando os alunos a se apropriarem de sua biblioteca. 
Rovilson José da Silva; Teba Silva Yllana; Felipe Martins Menck; Giovana Takahashi de Oliveira

Pedagogia, arquitetura e biblioteconomia: processos pedagógicos para reestruturar uma biblioteca escolar

Figura 7: Proposta de espaço de estudo individual com prateleira/divisória
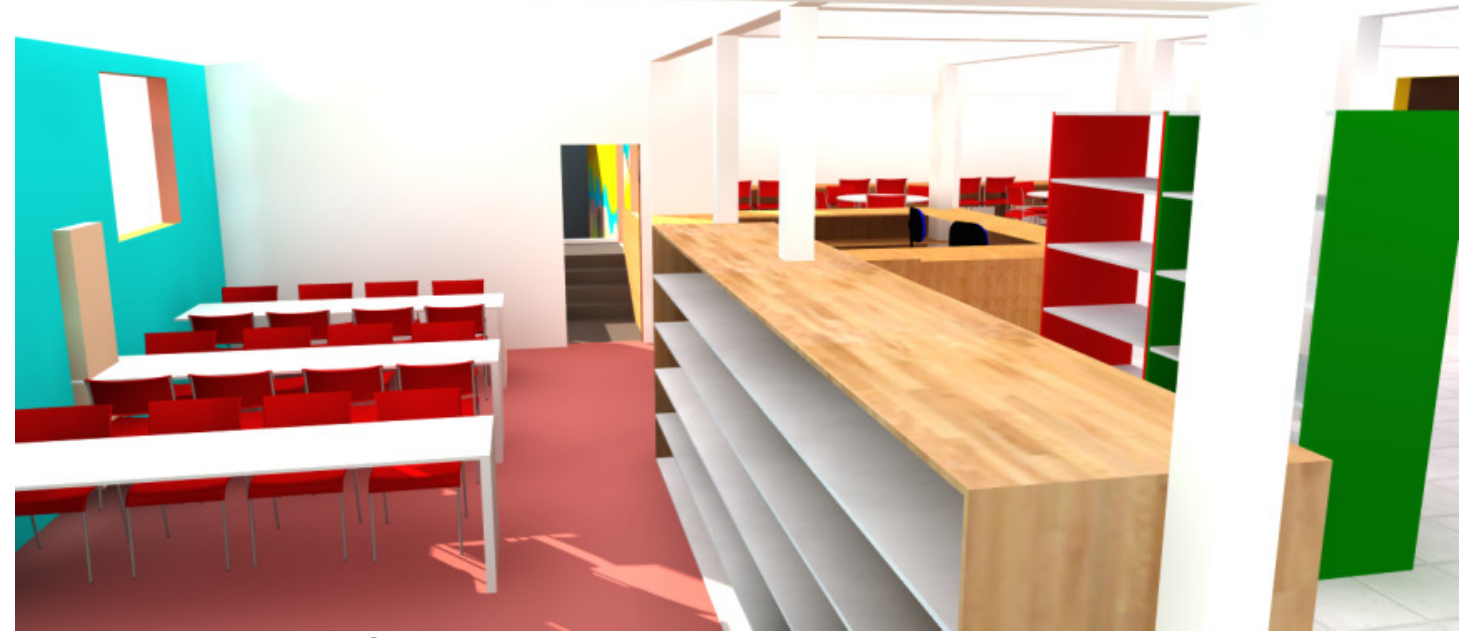

Fonte: Imagem de SketchUp realizada pelos extensionistas.

O balcão é a peça central do ambiente, pois dali é possível ter uma visão geral do ambiente e dos alunos usuários. Ao longo do tempo, ele mudou muitas vezes de localização, em lugares com muita insolação ou onde não era possível a visualização da biblioteca como um todo. A alocação proposta (figura 8) possibilita os educadores visualizarem todos os espaços da biblioteca e funciona também como elemento de transição suave de mudança de nível.

Figura 8: Proposta do balcão de atendimento central

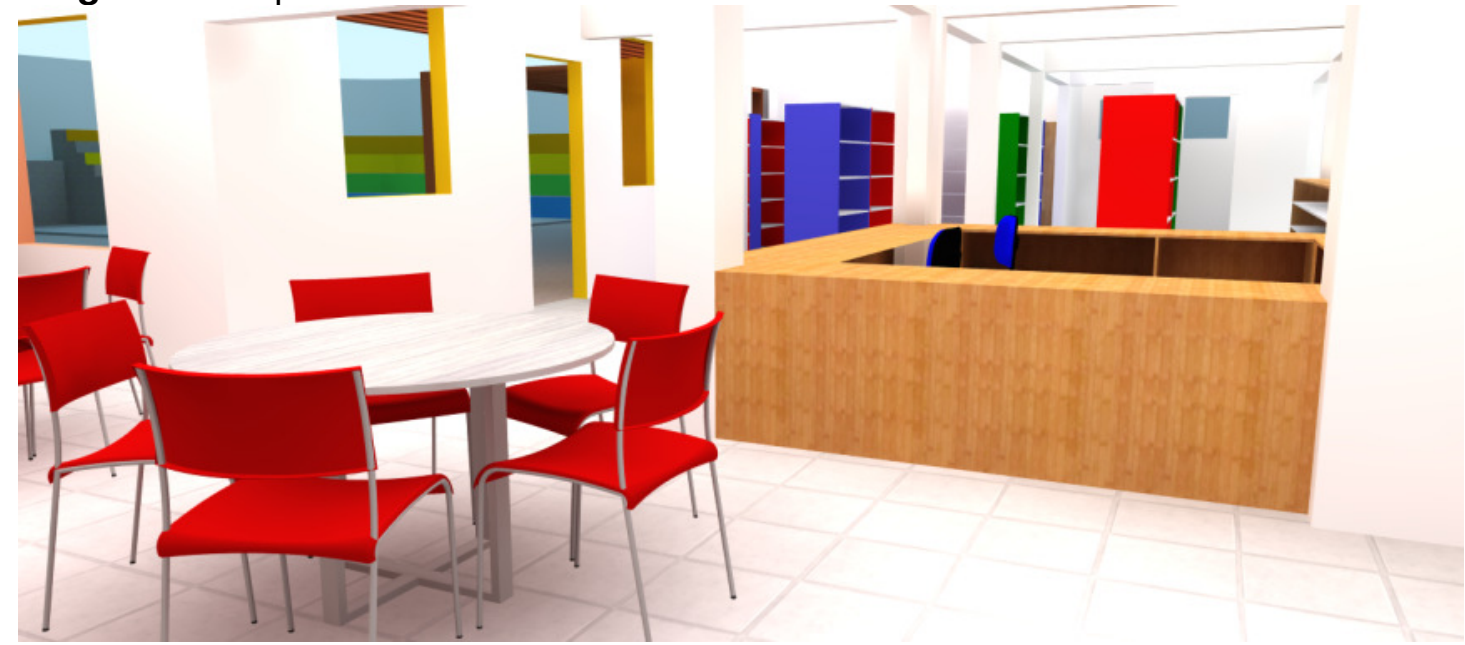

Fonte: Imagem gerada em SketchUp/ acervo dos extensionistas.

O pátio interno da biblioteca estava ocioso, abandonado e apresentava imenso potencial, configurando-se como uma extensão do prédio, sendo considerado um espaço para a leitura informal, em 
Rovilson José da Silva; Teba Silva Yllana; Felipe Martins Menck; Giovana Takahashi de Oliveira

Pedagogia, arquitetura e biblioteconomia: processos pedagógicos para reestruturar uma biblioteca escolar

contato com a natureza. Além disso, por conta das experiências escolares dos colaboradores do projeto, foram atribuídas ainda mais funções a esse espaço.

Para dar suporte a atividades como teatro, apresentações escolares, entre outros, foi projetado, conforme pode ser visualizado na figura 9, um palco e arquibancada com capacidade para aproximadamente 100 pessoas e dois cadeirantes, ela também serve como um lugar de descanso nos intervalos de aula ou de encontro entre alunos. A abertura do pátio para a escola sem a necessidade da passagem para biblioteca foi importante para minimizar o conflito de alunos utilizando a biblioteca como espaço formal, daqueles que procuram o espaço externo, informal para diálogo, descanso e divertimento.

Figura 9: Proposta para o pátio interno

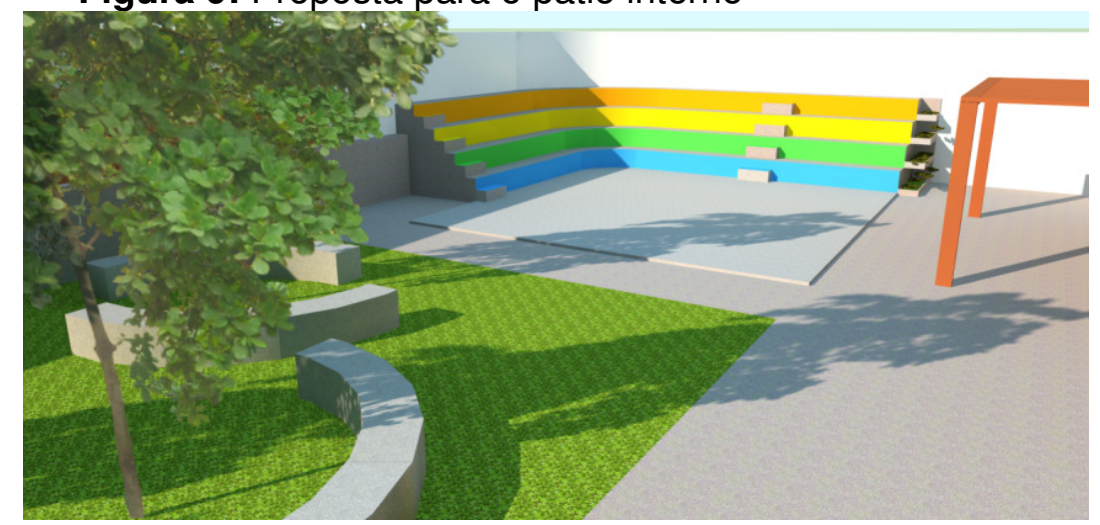

Fonte: Imagem gerada em SketchUp, acervo dos autores.

Por fim, é possível ver na figura 10, imagens gerais da proposta da biblioteca, que tem como principal objetivo tornar a biblioteca atrativa, utilizando mais cores que o prédio atual, além de cuidar da acessibilidade ao local sem obstáculos ou dificuldades para qualquer pessoa com deficiência física ou com mobilidade reduzida, portanto, pedagogicamente adequada à formação do aluno. 
Rovilson José da Silva; Teba Silva Yllana; Felipe Martins Menck; Giovana Takahashi de Oliveira

Pedagogia, arquitetura e biblioteconomia: processos pedagógicos para reestruturar uma biblioteca escolar

Figura 10: Visão geral da biblioteca / nova proposta

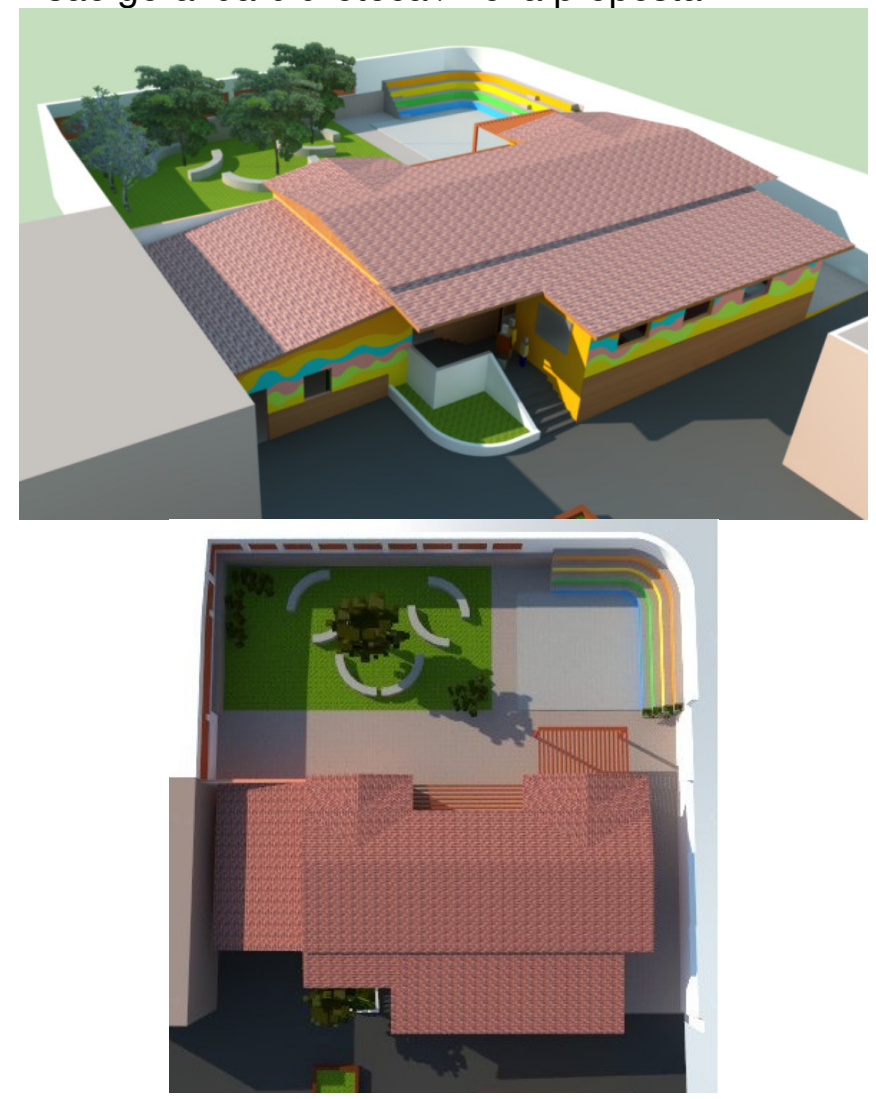

Fonte: Imagem gerada em SketchUp, acervo dos extensionistas.

\section{DISSEMINAÇÕES DO PROJETO}

Depois de elaborar o material gráfico do anteprojeto, foi iniciada a divulgação e apresentação dos resultados do Projeto de extensão em simpósios e seminários promovidos pela comunidade universitária, nas áreas temáticas da extensão e da educação. A montagem dessas apresentações deveria levar em consideração formas de apresentar ao público leigo o anteprojeto de forma didática e acessível. Essa preocupação se dá por conta de os ouvintes não estarem familiarizados à leitura de linguagem gráfica técnica, apesar de serem conhecedores da área de educação.

Para estabelecer essa comunicação, foram utilizados elementos constituintes do projeto na elaboração das peças gráficas confeccionadas, como a presença das cores escolhidas para utilização na fachada da biblioteca escolar, por exemplo. A elaboração de material 
Rovilson José da Silva; Teba Silva Yllana; Felipe Martins Menck; Giovana Takahashi de Oliveira

Pedagogia, arquitetura e biblioteconomia: processos pedagógicos para reestruturar uma biblioteca escolar

digital em três dimensões também ajudou a sedimentar a transmissão das ideias para os espectadores das apresentações, aproximando-os de uma compreensão mais completa da escala e intenção de cada intervenção sugerida e sua importância no conjunto da reestruturação arquitetônica e pedagógica proposta.

Nos debates que acompanharam as sessões de apresentação, os colaboradores tiveram contato muito positivo com outras pessoas não ligadas ao Projeto, pois elas contribuíram com suas opiniões, histórias e experiência sobre suas vivências de biblioteca escolar. É o caso de uma psicóloga, que assistiu a uma apresentação dos extensionistas no evento "Por Extenso - 3 Simpósio de Extensão da UEL 2014" e aprovou a preocupação de retomada, no processo de projeto, das experiências vividas em bibliotecas escolares pelos próprios colaboradores na época do ensino infantil e fundamental (SILVA et al., 2014).

Também, uma professora de matemática relatou que decidiu organizar a biblioteca de sua escola e compartilhou conosco sua história na XVI Semana da Educação e VI Simpósio de Pesquisa e Pósgraduação em Educação (PACHECO et al., 2015). Informou que quando se aposentou, resolveu mobilizar estudantes e familiares para organizar a biblioteca da escola onde trabalhava. Segundo seu relato, a participação e colaboração de todos da comunidade foi muito importante. Sua contribuição oral explicita a importância do entendimento da biblioteca escolar como espaço fundamental para o crescimento e o enriquecimento da formação dos alunos pelos docentes, e seu proativismo inspira. Ainda nesse evento científico, há discussão acerco do fazer pedagógico no processo readequação da biblioteca escolar (BÚFALO et al., 2015).

Além disso, em 2015, os professores orientadores do projeto apresentaram no Congresso Ibero-americano de Bibliotecas Escolares, CIBES 2015: Congresso Ibero-Americano de Bibliotecas Escolares, realizado na UNESP/Marília-SP, aspectos da mediação 
Rovilson José da Silva; Teba Silva Yllana; Felipe Martins Menck; Giovana Takahashi de Oliveira

Pedagogia, arquitetura e biblioteconomia: processos pedagógicos para reestruturar uma biblioteca escolar

pedagógica envolvida pelas áreas do projeto, ou seja, Arquitetura, Biblioteconomia e Pedagogia.

\section{CONSIDERAÇÕES PARCIAIS}

O Projeto de extensão está em andamento, portanto ainda serão necessárias várias adequações até a sua finalização. Foi possível constatar, como um dos primeiros resultados das readequações propostas à comunidade escolar, o fortalecimento do papel da biblioteca como parte importante da construção do aprendizado dos alunos pela sua crescente valorização na vida escolar. Essa constatação se confirma pelo aumento perceptível da frequência dos discentes na biblioteca nos períodos letivo e inverso. Algumas melhorias emergenciais foram executadas na parte física da biblioteca, como a troca do forro da cobertura e a mudança da disposição do acervo existente com o objetivo de retardar sua degradação por aspectos ambientais e facilitar o seu acesso pela comunidade escolar. A apresentação do anteprojeto arquitetônico para a escola e sua subsequente aprovação, com a sugestão de mudanças por meio do constante diálogo entre as partes, balizou o desenvolvimento do projeto executivo arquitetônico na extensão.

A interdisciplinaridade proposta desde o embasamento teórico até o desenvolvimento do projeto foi fundamental para a sua aprovação pelos usuários da biblioteca escolar, pois é preciso se preocupar em conhecer o perfil e as necessidades de quem vai utilizar o espaço para se desenvolver um projeto arquitetônico. Os diferentes pontos de vista abordados por cada um dos colaboradores, orientadores e teóricos estudados ampliou muito o universo do conhecimento disponível, proporcionando a construção de uma proposta que procurava atender às necessidades da comunidade escolar da forma mais abrangente possível. 
Rovilson José da Silva; Teba Silva Yllana; Felipe Martins Menck; Giovana Takahashi de Oliveira

Pedagogia, arquitetura e biblioteconomia: processos pedagógicos para reestruturar uma biblioteca escolar

\section{REFERÊNCIAS}

BARBALHO, Célia Regina Simonetti et al. (Org.). As Cartografias da Biblioteca. In: BARBALHO, Célia Regina Simonetti. Espaços e ambientes para leitura e informação. Londrina: $A B E C I N$, 2012, p. 93130.

BÚFALO, Kátia; SILVA, Rovilson José da; BORTOLIN, Sueli. Processo de readequação pedagógica da biblioteca do IEEL. In: SEMANA DA EDUCAÇÃO, 16.; SIMPÓSIO DE PESQUISA E PÓS-GRADUAÇÃO EM EDUCAÇÃO, 7., 2015. Londrina. Anais eletrônicos... Londrina:

Departamento de Educação, 2015, p.155-159. Disponível em:

<http://www.uel.br/eventos/semanaeducacao/pages/arquivos/ANAIS/RE SUMO/SABERES\%20E\%20PRATICAS/PROCESSO\%20DE\%20READ EQUACAO\%20PEDAGOGICA\%20DA\%20BIBLIOTECA\%20DO\%20IEE L.pd>f. Acesso em: 21 dez. 2015.

OLIVEIRA, Giovana Takahashi de. Estudo preliminar (B) elaborado para a biblioteca escolar do IEEL, em planta. 2014.

PACHECO, Camila Buono et al. Reestruturação arquitetônica e pedagógica da biblioteca escolar de uma escola pública. In: SEMANA DA EDUCAÇÃO, 16.; SIMPÓSIO DE PESQUISA E PÓS-GRADUAÇÃO EM EDUCAÇÃO, 6., 2015, Londrina. Anais... Londrina: Departamento de Educação, 2015. Disponível em: <http://www.uel.br/eventos/semanaeducacao/pages/anais-doevento.php>. Acesso em: 21 dez. 2015.

RIBEIRO, Giovana Luppi Pezarini. Estudo preliminar (A) elaborado para a biblioteca escolar do IEEL, em planta. 2014.

SILVA, Rovilson José da; YLLANA, Teba Silva; BORTOLIN, Sueli. Mediação pedagógica numa biblioteca de escola púbica em Londrina. In: CONGRESSO IBERO-AMERICANO DE BIBLIOTECAS ESCOLARES CIBES, 2015, Marília - SP. Anais eletrônicos... Marília - SP: Unesp, 2015.

Disponível

em: <http://fontes.marilia.unesp.br/eventos/index.php/cibes2015/CIBES2015/ paper/view/8>. Acesso em: 21 dez. 2015.

SILVA, Rovilson José da et al. Reestruturação arquitetônica e pedagógica da biblioteca de uma escola pública de Londrina. In: SIMPÓSIO DE EXTENSÃO DA UEL [Por Extenso], 3., 2014, Londrina Pr. Anais... Londrina - Pr: UEL, 2014.

SILVA, Rovilson José da. Projetar a Biblioteca da Escola: recomendações. In: BARBALHO, Célia Regina Simonetti. Espaços e ambientes para leitura e informação. Londrina: $A B E C I N, 2012$, p. 157172. 
Rovilson José da Silva; Teba Silva Yllana; Felipe Martins Menck; Giovana Takahashi de Oliveira

Pedagogia, arquitetura e biblioteconomia: processos pedagógicos para reestruturar uma biblioteca escolar

VIDULLI, Paola. Diseño de bibliotecas: guia para planificar y proyectar bibliotecas públicas. Gijón (Asturias): TREA, 1998.

\section{Title}

Pedagogy, Architecture and Librarianship: pedagogical procedures for a school library restructure

\section{Abstract}

Introduction: School libraries in general are still not able to provide, to their readers, a space where they can feel welcomed physically, psychologically and culturally. The library of the State Educational Institute of Londrina (IEEL) is not an exception.

Objective: Disseminate the interventions conducted in IEEL's library by the extension project "Formation of the Reading Mediator in public school" team from 2012 to 2015.

Methodology: The procedures were built using the collaborative methodology and had the participation of teachers and students from UEL, directors, pedagogical team and attendants of the IEEL's library.

Results: Interferences were conducted in the spatial school library readaptation associated with reading pedagogical mediation, aiming readers' formation. To achieve that, several meetings of study and research, discussion about libraries, their spaces and roles were held, as recognition of library space at IEEL and UEL's central library and construction of a comfortable and pleasant architectural project were made.

Conclusions: The first spatial adjustments in the school library have already been showing their effects because they have been answering to the needs of use of the library space by the school community satisfactorily.

Keywords: School library. Pedagogical procedures. Architectural restructuring. Pedagogy. Architecture. Librarianship

\section{Titulo}

Pedagogía, Arquitectura y Bibliotecología: procesos pedagógicos para estructurar una biblioteca escolar

\section{Resumen}

Introducción: Las bibliotecas escolares, en general, aun no pueden proporcionar a los lectores, un espacio que se sientan acogidos, psicológica y culturalmente, por lo tanto la biblioteca del Instituto Estatal de Londrina Educación (IEEL), no es una excepción.

Objetivo: Difundir las interferencias hechas en la biblioteca de IEEL por el equipo del proyecto de extensión "Lectura Entrenamiento Facilitador en la escuela pública" en el período 2012-2015. 
Rovilson José da Silva; Teba Silva Yllana; Felipe Martins Menck; Giovana Takahashi de Oliveira

Pedagogia, arquitetura e biblioteconomia: processos pedagógicos para reestruturar uma biblioteca escolar

Metodología: Los procedimientos fueron construidos usando la metodología colaborativa y contó con la participación de profesores y estudiantes de la UEL, director, equipo pedagógico y los profesionales de la biblioteca del IEEL.

Resultados: Fueron hechos interferencia en la adaptación espacial de biblioteca en la escuela asociada con la mediación pedagógica de la lectura, con la finalidad de formar lectores. Por lo tanto, hubo numerosas reuniones de estudio y investigación, la discusión acerca de la biblioteca, su espacio y sus funciones, el reconocimiento del espacio de la biblioteca del IEEL y en la biblioteca central UEL, la construcción del diseño arquitectónico cómodo y agradable.

Conclusiones: Los primeros ajustes espaciales de la biblioteca de la escuela pública ya ha tenido efecto, pues se ha dado a las necesidades de uso de este entorno por la comunidad escolar de forma satisfactoria.

Palabras clave: Biblioteca escolar. Procesos pedagógicos. Reestructuración arquitectónica. Pedagogía. Arquitectura. Bibliotecología.

Recebido em: 26.12.2015

Aceito em: 20.03.2016 